\title{
IMPACTO DA ESPECIFICIDADE DE ATIVOS NOS CUSTOS DE TRANSAÇÃO, NA ESTRUTURA DE CAPITAL E NO VALOR DA EMPRESA
}

\author{
Marcelo Coletto PohImann \\ Professor Ms. do Departamento de Contabilidade da FACE/PUC - RS \\ E-mail: mar.cp@terra.com.br \\ Andson Braga de Aguiar \\ Mestrando em Controladoria e Contabilidade pela FEA/USP \\ E-mail: andsonbraga@yahoo.com.br \\ Aldo Bertolucci \\ Doutorando em Controladoria e Contabilidade pela FEA/USP \\ E-mail: abertolucci@ hotmail.com \\ Eliseu Martins \\ Professor Titular do Depto. de Contabilidade e Atuária da FEA/USP \\ E-mail: emartins@usp.br
}

\section{RESUMO}

Este artigo discute o conceito de especificidade de ativos, o seu papel dentro da Teoria de Custos da Transação e explora os seus efeitos na estrutura de capital e no valor da empresa. Objetiva-se, através de uma abordagem empírico-analítica, explicar de que maneira a especificidade de ativos influencia as decisões e a conduta dos agentes econômicos. Uma ampla variedade de pesquisas anteriores comprova a existência de efeitos relevantes derivados desse fator. Testa-se a hipótese de que baixos níveis de endividamento geral e de longo prazo estariam associados a firmas atuantes em mercados com maior grau de concentração industrial. Firmas que apresentam tal comportamento para essas variáveis teriam um provável maior grau de especificidade de ativos. Para tanto, utiliza-se a técnica multivariada Cluster Analysis sobre uma amostra obtida junto à publicação Exame Melhores e Maiores abrangendo o ano de 2001. Os resultados foram estatisticamente significativos, tendo sido identificados dois clusters distintos: um das firmas com um provável maior grau de especificidade de ativos, e outro daquelas com menor grau.

Palavras-chave: custos da transação, especificidade de ativos, avaliação de empresas, estrutura de capitais, concentração industrial.

\section{ABSTRACT}

This paper discusses the assets specificity concept and its role in Transaction Cost Theory and explores its effects on capital structure and company value. Adopting an empirical-analytical approach, the purpose is to explain how assets specificity influences the decisions and behavior of economics agents. A wide variety of earlier studies prove the existence of relevant effects derived from this factor. The hypothesis is tested that low levels of general and long-term indebtedness would be associated with firms active in markets with a higher degree of industrial concentration. Firms displaying this kind of behavior for these variables would probably have a higher degree of assets specificity. A multivariate Cluster Analysis is applied to a sample of companies from Exame Melhores e Maiores for the year 2001. Results were statistically significant, with two different clusters: companies with a higher probable degree of assets specificity, as opposed to those with a lower probable degree of assets specificity.

Keywords: transaction costs, assets specificity, valuation, capital structure, industrial concentration. 


\section{INTRODUÇÃO}

O presente trabalho tem por objeto o estudo dos aspectos relacionados à especificidade de ativos e seu reflexo nos custos de transação da firma, que são todos aqueles custos relacionados ao modo de gerir os negócios, aos processos e aos contratos firmados pela organização para atingir seus objetivos. Além disso, analisa-se o impacto da presença de ativos específicos na estrutura de capital e no valor da empresa.

A abordagem do tema se dá sob o enfoque da Teoria dos Custos de Transação, um conjunto estruturado de proposições que nasceu e se desenvolveu buscando responder a perguntas do tipo: por que a firma existe? Como e por quê se dá o processo de verticalização? Essa doutrina vai além do estabelecido pela teoria neoclássica, que considera a firma como incorrendo, significativamente, apenas em custos de produção, para tratar da magnitude e dos efeitos dos custos de transação associados aos contratos e estruturas de governança presentes na firma. Seus expoentes são Ronald Coase e Oliver Williamson.

A escolha do tema justifica-se pela relevância da contribuição dada pela referida teoria à evolução do estudo da firma no campo microeconômico, além de servir constantemente de referencial teórico para inúmeras pesquisas, referidas na Seção 6, que procuram explicar o comportamento de determinadas variáveis como endividamento, grau de concentração de indústrias, risco, dentre outras.

Trata-se de uma pesquisa exploratória de caráter empírico-analítico que procura, a partir de dados relativos às maiores empresas brasileiras e tomando por base pesquisas empíricas anteriores, testar hipóteses que dizem respeito à relação entre a especificidade de ativos e o comportamento de determinadas variáveis.

$\mathrm{Na}$ segunda seção, é resenhada a Teoria dos Custos de Transação e suas principais dimensões. $\mathrm{Na}$ terceira seção, a especificidade de ativos é definida e são analisadas as conseqüências da presença desses ativos nas transações da firma. Na quarta seção, são referidos aspectos relativos ao impacto dos ativos específicos no endividamento da firma. $\mathrm{Na}$ quinta seção, é discutido como os ativos específicos podem afetar o valor da empresa. Na sexta seção, são relatados os resultados de pesquisas anteriores acerca do assunto. Nas seções seguintes, são apresentadas as hipóteses de pesquisa, os dados e a metodologia utilizados, assim como os resultados encontrados e as conclusões do estudo.

\section{CUSTOS DE TRANSAÇÃO}

A questão relativa aos custos de transação ganhou destaque a partir do desenvolvimento da chamada Teoria dos Custos de Transação (TCT), inaugurada com os estudos de Ronald Coase e aprofundada por Oliver Williamson. Até a publicação do artigo pioneiro de Ronald Coase em 1937, The Nature of the Firm, a teoria econômica tratava em detalhe apenas dos custos de produção. Embora se reconhecesse a existência também de custos de transação, isto é, que não apenas o ato de produzir, mas o ato de comprar e vender acarretava custos, supunha-se, em geral, que os custos associados às transações econômicas eram negligenciáveis, de tal forma que os únicos custos que realmente importavam eram os custos de produção.

De acordo com Fiani (2002, p. 267), Coase (1937), em seu artigo, busca a definição da empresa que corresponda ao que ela é no mundo real. Para isso faz uma pergunta primária, mas que, surpreendentemente, nenhum dos mais importantes economistas até aquele momento havia feito: por que existem empresas? Dito de outra forma, porque existem organizações dirigindo o processo produtivo em que relações hierárquicas, definidas pela subordinação dos empregados à direção da empresa, determinam como se deve organizar a produção?

Assim, é necessário entender por que a produção não pode ser levada a cabo por uma série de agentes individuais, formando uma cadeia em que cada um comprasse daquele que se encontrasse em uma etapa anterior do processo de produção, até que o último produtor na cadeia vendesse o produto acabado ao consumidor final. Em outras palavras, é preciso explicar o que leva diferentes etapas do processo produtivo a serem integradas verticalmente dentro de uma empresa. Organizações que decidem, hierarquicamente, a alocação dos fatores de produção no seu interior, substituindo o mecanismo de mercado, existem porque os custos de transação, ou seja, os custos de recorrer ao 
mercado, são significativos entre as etapas do seu processo de produção.

O artigo de Coase (1937) deu início, dessa forma, ao estudo das condições sob as quais os custos de transação deixam de ser desprezíveis e passam a ser um elemento importante nas decisões dos agentes econômicos, contribuindo para determinar a forma pela qual são alocados os recursos na economia. A análise dessas condições, assim como das conseqüências dos custos de transação para a eficiência do sistema, constituem o objeto da Teoria dos Custos de Transação (TCT).

A essa resposta, ou seja, do porquê da existência de empresas, se segue uma outra pergunta: dado que existem empresas, mas que estas, também, não são absolutas na organização do processo produtivo, pois há um grande número de transações que se dão pelo mercado, quais são os limites das empresas para organizar a produção? Quando é mais interessante produzir sob a direção de uma hierarquia, e quando é mais interessante deixar que o mercado, através do mecanismo de preços, coordene a produção? Em outras palavras, por que o mercado não é eliminado, produzindo-se tudo em uma única e gigantesca empresa?

Segundo Farina et al. (1997, p. 49), a proposta original de Coase (1937), relacionando a forma organizacional aos custos de transação, repercutia modestamente na literatura econômica, particularmente em estudos empíricos, a medida em que não se tratava de uma hipótese refutável. O modo como Coase (1937) apresentava seu insight não permitia testes empíricos por falta de base de comparação e/ ou observação dos custos de transação.

Considerando a transação como unidade de análise, Williamson (1985) preocupa-se em atribuir dimensões a essas transações, utilizando elementos objetivos e observáveis. A proposição de Coase (1937), finalmente, poderia ser testada: os elementos observáveis permitiriam deduzir o nível de custos de transação e qual a forma organizacional eficiente para reger essa determinada transação.

O objetivo central da contribuição de Williamson (1985) é compreender as origens e funções das diversas estruturas de empresas e do mercado, ou seja, das instituições econômicas do capitalismo. A questão é como essas instituições (mercados, firmas e contratos) lidam com os problemas vinculados à transação, uma vez que a utilização do mecanismo de mercado implica custos. Por transação entende-se a transferência de bens e/ ou serviços entre agentes que estão separados por etapas de produção tecnologicamente distintas, estando associados a ela custos de planejamento, adaptação e monitoramento. Colocada nesses termos, as instituições econômicas do capitalismo têm como função principal, embora não exclusiva, reduzir custos de transação.

Em suas relações econômicas a montante ou a jusante, as firmas podem optar por pelo menos um dos três modos de coordenação (estruturas de governança), selecionado como aquele que minimiza os custos de transação: (1) via mercados; (2) via formas híbridas; e (3) via hierarquia (integração vertical). A opção das firmas pela forma de coordenação mais adequada é feita analisando-se três parâmetros da transação: a especificidade dos ativos, a freqüência e a incerteza (GUEDES, 2000, p. 8).

A incerteza presente nas relações está vinculada, principalmente, à existência do comportamento oportunista, que torna imprevisível a identificação de possíveis desvios futuros de comportamento e compromissos, e difícil a identificação de falsos sinais e informações por parte dos envolvidos na transação.

A freqüência refere-se ao número de vezes das transações e ao seu caráter recorrente. Assim, quanto mais freqüentemente uma transação é realizada, mais dependentes tornam-se as sua partes. A especificidade dos ativos é tratada na próxima seção.

Merece registro, por fim, que a TCT tem seus críticos e opositores. Ghoshal e Moran (1996, p. 14), por exemplo, argumentam que as prescrições oriundas da TCT de Williamson são não apenas erradas, mas também perigosas para os gestores das organizações devido às suas presunções e aos seus fundamentos lógicos, especialmente a questão do oportunismo dos agentes.

Outros autores (PHAN e SOMMER, 1999; PLUNKET e SAUSSIER, 2002; NICKERSON, HAMILTON e WADA, s.d.; CHABAUD, s.d.) têm realçado a contribuição da TCT mas, por outro lado, apontam certas limitações, especialmente a impossibilidade de a teoria explicar todos os aspectos que cercam o surgimento e a evolução das organizações. 


\section{ESPECIFICIDADE DE ATIVOS}

Ativo é definido pelo IASB - International Accounting Standards Board (2001) como "[...] um recurso controlado pela entidade como resultado de eventos passados e do qual se espera que futuros benefícios econômicos resultem para a entidade". Os ativos podem ser classificados pelo menos dentro de três concepções: 1) quanto ao grau de liquidez circulante, realizável a longo prazo e imobilizado; 2) quanto à existência física - tangível e intangível; e 3) quanto à reempregabilidade - ativos específicos e não-específicos. A primeira concepção é empregada tradicionalmente na classificação dos ativos para efeitos de elaboração das demonstrações contábeis. A segunda está relacionada à existência física do ativo, à possibilidade ou não de um ativo ser tocado. A terceira está relacionada com a possibilidade de se utilizar um determinado ativo em outra atividade que não a que lhe é específica.

Considerando essa terceira concepção de classificação de ativos, ativos específicos são definidos, segundo Farina et al. (1997, p. 84), como aqueles que não são reempregáveis a não ser com perda de valor. Essa característica, aliada ao pressuposto do oportunismo e à incompletude dos contratos, torna o investimento nesses ativos sujeito a riscos e problemas de adaptação, gerando custos de transação. A especificidade é a característica de um ativo que expressa a magnitude de seu valor e é dependente da continuidade da transação da qual ele é específico. Quanto maior a especificidade, maiores serão os riscos e problemas de adaptação e, portanto, maiores os custos de transação. Por depender da continuidade dessa transação, trata-se de um conceito indissociável do tempo.

A definição acima aproxima muito a especificidade de ativos do conceito de sunk cost, embora não haja uma identidade perfeita entre ambos. Esse último refere-se aos custos fixos incorridos e irrecuperáveis. Portanto, se a compra de uma máquina é considerada sunk cost, não é possível vendê-la, o que sugeriria tratar-se de um ativo específico. No entanto, nem sempre um sunk cost é específico a uma transação, apesar de freqüentemente sê-lo.

Rocha (2002, p. 241) refere-se ao caso da empresa que aluga uma loja em um centro comercial, comprometendo-se por um prazo mínimo de um ano.
$\mathrm{Na}$ hipótese de ela descontinuar o negócio antes desse prazo, o valor pago ou a pagar pelo aluguel é um típico sunk cost. Essa é a essência dos custos irrecuperáveis. Uma vez que a empresa tenha se comprometido com eles, não pode voltar atrás em sua decisão. Dessa maneira, ainda que se constitua em um custo para a empresa, a despesa realizada ou por realizar não se constitui em um custo econômico strictu sensu por não poder ter uso alternativo.

A presença de diferentes instrumentos através dos quais se possa investir em custos irrecuperáveis pode, então, influenciar, pesadamente, a estrutura de mercado que deverá prevalecer, à medida que funciona como uma maneira de deter a entrada de novas empresas. Assim, mercados em que é possível a realização constante de investimentos em custos irrecuperáveis devem apresentar estruturas mais concentradas do que mercados em que a realização de investimentos irrecuperáveis é apenas ocasional.

O problema associado com a especificidade de ativos é que, uma vez que o investimento em um ativo específico tenha sido feito, comprador e vendedor passam a se relacionar de uma forma exclusiva ou quase exclusiva. A especificidade de ativos é uma condição necessária para que o risco associado a atitudes oportunistas seja significativo; caso contrário, a própria rivalidade entre os numerosos agentes aptos a participarem da transação, tanto no papel de vendedores como de compradores, reduziria a possibilidade de atuações oportunistas (FIANI, 2002, p. 272).

O caráter crescente de transações envolvendo ativos específicos reduz, progressivamente, a vantagem que o mercado oferece (economias de escala), enquanto os custos derivados de negociar, redigir, implementar e verificar a execução adequada das cláusulas contratuais crescem (em resumo, os custos de transação). É da comparação desses dois termos (economias de escala versus custos de transação) que caberá a decisão final quanto à forma institucional mais adequada para a organização da transação: via mercado ou via estrutura hierárquica da empresa.

Esse ponto é importante e deve ser ressaltado. A condição para a obtenção de economias de escala é que o mercado seja suficientemente extenso para que esses ganhos possam ser aproveitados. Isso nada mais é do que a existência de um grande 
número de transações, o que por sua vez significa que o ativo transacionado, produzido e comercializado pela firma, possui um grau de especificidade bastante baixo. Como conseqüência, o mesmo ativo pode ser oferecido a um número razoavelmente grande de clientes potenciais, e, portanto, o produtor ganha escala, podendo oferecer o ativo em questão a um preço mais baixo do que o custo que o demandante teria se produzisse o ativo apenas para si mesmo.

Ao mesmo tempo, por ser um ativo de baixo grau de especificidade, a soma dos custos de negociar, redigir e garantir a execução de um contrato deixa de ser expressiva. Sendo o ativo pouco específico, não envolve complexidade e incerteza. Não envolvendo complexidade e incerteza, a negociação e a redação dos contratos não pressionam a racionalidade limitada dos agentes. Nesse caso, têm-se transações em grande número, o que significa muitos vendedores e compradores no mercado, limitando, assim, as vantagens de qualquer uma das partes em adotar atitudes oportunistas: sempre se pode encontrar um outro fornecedor ou um outro cliente para transacionar o ativo.

O mesmo já não ocorre caso a transação sob análise seja do gênero small numbers. Nesse caso, o ativo é produzido tendo em vista as necessidades específicas do demandante; logo, há pouca ou nenhuma possibilidade de o ativo ser produzido para outros demandantes e com isso as vantagens em termos de escala de produção (com a conseqüente redução de custos) se perdem, ao mesmo tempo em que os problemas de negociação e implementação do contrato aumentam. Passa a ser mais barato para o demandante produzir ele mesmo o ativo em questão do que recorrer a uma transação via mercado em termos de custo final. Isso porque, produzindo ele mesmo, não há perda de escala significativa, uma vez que sendo o insumo específico, seu mercado é muito limitado.

Williamson (1985, p. 55) identifica pelo menos quatro fontes de especificidade de ativos:

1. Especificidade de localização: decisões prévias, visando minimizar custos de estocagem e transporte, podem gerar ativos com especificidade de localização, que uma vez estabelecidos podem ser de difícil ou impraticável transporte. Uma subestação de distribuição de energia elétrica, por exemplo.

2. Especificidade física: características de design podem reduzir o valor do ativo em uma aplicação alternativa. Equipamentos sob encomenda se enquadram nesse caso.

3. Especificidade de capital humano: esse tipo de especificidade surge, fundamentalmente, através do processo "aprender fazendo" (learningby-doing) dos empregados de uma empresa. Isso é especialmente verdadeiro para a mãode-obra alocada nos laboratórios de pesquisa e desenvolvimento das empresas.

4. Especificidade de ativos dedicados: surge nos casos em que o fornecedor faz um investimento que, exceto pela perspectiva da venda de uma quantidade expressiva de produto para determinado cliente, não seria feito. Como exemplo, temos os investimentos de fornecedores de autopeças para atender a uma montadora.

Posteriormente, Williamson (1991a) refere mais duas espécies: (1) a especificidade de marca, referente ao capital - nem físico nem humano - que se materializa na marca de uma empresa, sendo particularmente relevante no mundo das franquias; e (2) especificidade temporal, em que o valor de uma transação depende, sobretudo, do tempo em que ela se processa, sendo especialmente relevante no caso da negociação de produtos perecíveis (FARINA ET AL., 1997, p. 86).

\section{ESPECIFICIDADE DE ATIVOS E ESTRUTURA DE CAPITAL}

Balakrishnan e Fox (1993, p. 3) apresentam uma investigação empírica acerca da importância dos ativos especializados e outras características idiossincráticas ou únicas da firma na explicação da variação na estrutura de capital dentre as mesmas. Os resultados mostram que os efeitos das especificidades da firma contribuem para explicar a variância da alavancagem, sugerindo uma forte ligação entre estratégia e estrutura de capital.

Recentes desenvolvimentos da TCT sugerem que a estrutura de capital pode ter mais a ver com fatores estratégicos e de controle do que puramente 
fatores financeiros (WILLIAMSON, 1988). Uma firma, freqüentemente, investe em ativos específicos buscando assegurar vantagens competitivas pela diferenciação. Esses ativos afetam a capacidade da firma de tomar empréstimos. Por definição, ativos específicos não podem ser reempregados em outros usos sem perdas e, portanto, dificilmente são aceitos como uma garantia de empréstimos.

Muitos ativos específicos são intangíveis - por exemplo, pesquisa e desenvolvimento e propaganda - sendo difícil medi-los e avaliá-los. Transações com tais ativos serão afetadas pela assimetria informacional entre insiders e outsiders da firma. Conseqüentemente, eles poderão ser negociados a preços inferiores e, se a firma for liquidada, o seu valor de mercado cairá muito.

Para a firma, os ativos específicos criam tanto problemas quanto oportunidades. O problema é que a possibilidade de a firma financiar esses ativos com capitais de terceiros é limitada pela natureza desses próprios ativos. Por outro lado, a firma, também, tem a oportunidade de desenhar e gerenciar estruturas de governança e relacionamentos de modo que esse problema seja mitigado. A habilidade da firma de administrar o relacionamento com os financiadores torna-se fator-chave de vantagem competitiva. Uma implicação empírica disso é que os efeitos da especificidade da firma terão um significativo impacto na estrutura de capital.

Muitos estudos empíricos anteriores, a maioria feitos por economistas, têm centrado foco nas vantagens fiscais e nos riscos de falência como fatores de explicação das variações cross-sectional da alavancagem. Associadas com a hipótese dos custos decorrentes do risco de falência é a noção de que as firmas, numa mesma indústria, enfrentando as mesmas condições de suprimento e demanda, terão basicamente as mesmas características de risco. Isso implica que a alavancagem variará sistematicamente dentre as indústrias.

Balakrishnan e Fox (1993, p. 3) investigaram, simultaneamente, a importância das características únicas da firma e do setor na determinação da sua estrutura de capitais. Os resultados encontrados indicam que os efeitos das especificidades da firma são mais importantes na explicação da variação cross-sectional da alavancagem, entendida como a proporção de capitais de terceiros no financiamento do ativo total.
O relacionamento entre a alavancagem e certos determinantes da estrutura de capital, tais como vantagens fiscais e risco do negócio, também são condicionados pela presença de efeitos da especificidade. Tomando essas duas evidências juntas, os autores são levados a acreditar que a capacidade da firma de tomar empréstimos e, portanto, sua estrutura de capital, estão intimamente ligadas à estratégia do negócio e à natureza dos ativos e habilidades exigidas para implementar a estratégia.

Williamson (1988) argumenta que capitais de terceiros e capitais próprios deveriam ser vistos como diferentes formas de estrutura de governança. $O$ capital de terceiro, como o mercado, é menos intervencionista e os credores podem exercer controle sobre a firma apenas se ela não adimplir o empréstimo ou violar cláusulas contratuais de alguma forma. O capital próprio é similar à estrutura hierárquica. Os direitos dos acionistas e sócios são muito mais gerais do que aqueles dos credores. Eles podem exercer controle através dos diretores, monitorando a ação dos gestores e intervindo nas decisões estratégicas sempre que necessário.

Usando a estrutura da TCT, Williamson (1988) argumenta que o tipo de governança escolhido capital de terceiro ou próprio - dependerá das características dos ativos empregados no empreendimento, particularmente sua reempregabilidade para outros usos. A relação entre a natureza dos ativos e o controle derivado do tipo de financiamento fornece um link para a estratégia de negócio da firma.

Afirmam Balakrishnan e Fox (1993, p. 7) que muitos pesquisadores em estratégia elastecem a importância de ativos específicos, recursos, habilidades, relacionamentos e investimentos como fontes primárias da vantagem competitiva das empresas. A relação entre ativos específicos e estrutura de capital, entretanto, não tem sido objeto de questionamento ultimamente. Ativos específicos podem reduzir custos, incrementar a qualidade e capacitar a firma para diferenciar seus produtos e serviços dos seus competidores. Tais ativos específicos - especialmente intangíveis como pesquisa e desenvolvimento, marca e outros investimentos de reputação - podem ser difíceis para os outsiders controlarem, compreenderem e avaliarem. Isso pode afetar a estrutura de capital da firma através de custos de falência que refletem a perda de valor da firma 
devido à possibilidade - ou o aumento dessa - de ocorrência de financial distress.

\section{ESPECIFICIDADE DE ATIVOS E VALOR DA EMPRESA}

Conforme já ressaltado na Seção 3, os ativos específicos são aplicações de recursos de capital que têm baixos valores para o segundo melhor uso. Assim, o grau de especificidade dos ativos para qualquer firma é uma função da uniqueness dos seus ativos, a proporção de ativos únicos em relação ao ativo total, e se um mercado secundário eficiente existe para esses ativos.

O valor de um empreendimento estará, fortemente, ligado a esse grau de especificidade, de modo que, numa hipótese de descontinuidade, ele será reduzido drasticamente em função de não ter a mesma utilidade em outra aplicação. Logo, ao se avaliar uma empresa, deve-se levar em conta a presença ou não desse gênero de ativo, isto é, o grau de especificidade do mesmo.

Via de regra, as técnicas e procedimentos de avaliação de empresas em continuidade referidos pela doutrina têm como ponto de partida o fluxo de caixa projetado do empreendimento, a partir de expectativas que, na maior parte das vezes, são baseadas no comportamento passado de variáveis como vendas, custos, despesas e resultados.

Assumindo-se a existência de risco ou incerteza associados aos eventos futuros, obviamente que a avaliação torna-se um exercício de projeção, em que diversos cenários alternativos possíveis ou prováveis devem ser considerados, com as respectivas probabilidades associadas.

Logicamente, deve-se considerar como possível de ocorrer o evento insucesso, em que o empreendimento seria abandonado ou descontinuado. Nessa hipótese, uma perda estaria associada a esse evento. Caso esse empreendimento envolva ativos específicos, essa perda será bem mais acentuada do que na hipótese contrária. Logo, o valor presente dos fluxos de caixa futuros de um investimento vinculado a ativos com alto grau de especificidade deve ser menor do que aquele com baixo grau.

Essa situação pode ser ilustrada pelo seguinte exemplo hipotético: um investidor tem duas opções de aplicação de seu capital, sendo a primeira a instalação de uma livraria em um grande shopping center da cidade. A outra opção é a instalação de um silo para armazenar trigo em uma determinada região agrícola situada no interior do país, longe dos grandes centros. $O$ valor do investimento em ambos os negócios é de $\$ 500.000,00$, sendo o risco de sucesso e de insucesso estimados em, respectivamente, $60 \%$ e $40 \%$. No primeiro empreendimento, o valor de liquidação dos ativos, no caso de descontinuidade, é de \$ 400.000,00; no segundo, esse valor cai para \$ $100.000,00$, em função de seu grau de especificidade. No caso de sucesso, ambos os empreendimentos gerarão um fluxo de caixa de $\$ 1.000 .000,00$. A matriz de pagamentos ficaria assim:

Tabela 1 - Matriz de pagamentos.

\begin{tabular}{l|c|c}
\multicolumn{1}{c|}{ Itens } & Loja no shopping & Silo \\
\hline Sucesso (60\% sobre o fluxo total de caixa) & $600.000,00$ & $600.000,00$ \\
\hline $\begin{array}{l}\text { Insucesso (40\% sobre a diferença entre o valor } \\
\text { do investimento e o valor de liquidação dos } \\
\text { ativos na descontinuidade) }\end{array}$ & & $(160.000,00)$ \\
\hline Valor presente líquido do investimento & $(40.000,00)$ & $440.000,00$ \\
\hline
\end{tabular}

No exemplo acima, pode-se perceber o que acontece quando existem alternativas de investimentos com diferentes graus de especificidade de ativos. Apesar de apresentarem fluxos de caixa idênticos na hipótese de continuidade do negócio, o que levaria a um mesmo valor presente, na hipótese de o negócio não ser bem sucedido o investimento na instalação do silo revela-se, significativamente, mais oneroso do que a loja no shopping. Como já referido nas seções 3 e 4 , a presença de um maior grau de especificidade de ativos implica em maior risco e, naturalmente, em maiores custos de transação.

A literatura que trata da avaliação de empresas costuma abordar a questão sob o ponto de vista 
estritamente financeiro, enfatizando técnicas e procedimentos de mensuração do valor presente líquido dos fluxos de caixa projetados a partir de séries históricas de variáveis contábeis e financeiras.

Martins et al. (2001, p. 265-266) afirmam que a avaliação de uma empresa, normalmente, se inicia pelas demonstrações contábeis. Devido, porém, à adoção dos princípios contábeis e à influência da legislação tributária, elas geralmente são incapazes de refletir o valor econômico de um empreendimento. Dentre os aspectos que dificultam a utilização das demonstrações contábeis para a obtenção de razoável aproximação do valor econômico de uma empresa, esses últimos autores destacam os seguintes:

1. os relatórios contábeis, normalmente, se baseiam em custos históricos afastados dos valores correntes;

2. alguns itens, principalmente as contas a receber, estão por seu valor futuro, quando o adequado seria o valor presente;

3. o conservadorismo tende a subestimar os valores dos ativos;

4. existem várias operações relevantes que, normalmente, não são registradas (off-balance sheet), tais como: arrendamento mercantil, posições em derivativos, garantias, goodwill etc.

Concluem esses autores que as demonstrações contábeis são geralmente inadequadas para a identificação do valor econômico de um empreendimento. Só em circunstâncias muito específicas, poderse-ia usá-las para essa tarefa. Ressalvam, por fim, que, paradoxalmente, a avaliação judicial de empresas, geralmente, baseia-se nas demonstrações contábeis. Em pouquíssimos casos, são efetuados ajustes e/ou cálculos rudimentares, à exceção do fundo de comércio.

Com respeito ao item 4 acima, é de ressaltar que, em muitas situações, parcela significativa dos ativos específicos da firma se constituem, na verdade, de intangíveis, ligados a investimentos ditos de reputação, como pesquisa e desenvolvimento, propaganda, qualificação do pessoal etc. São itens que agregam valor ao negócio assumindo-se a continuidade do empreendimento; numa situação de descontinuidade, à exceção de valores associados à marca, que podem ser negociados, tais ativos teriam valor de liquidação muito inferior ao que foi investido inicialmente.

\section{PESQUISAS ANTERIORES}

Segundo Fiani (2002, p. 282), o primeiro esforço sistemático de examinar empiricamente a TCT foi publicado em 1982, por Kirk Monteverde e David Teece. Em seu trabalho, esses autores examinaram a escolha entre integrar verticalmente ou recorrer ao mercado das empresas Ford e General Motors nos Estados Unidos. A partir de uma lista de 133 itens de componentes automotivos, foi observado se eram produzidos internamente pelas empresas ou comprados de fornecedores. A hipótese era de que o fator determinante na escolha era o esforço de engenharia aplicado a cada um desses componentes, o que identificaria uma especificidade de ativos humanos. Dessa forma, quanto maior o esforço de engenharia em um dado componente, maiores as chances desse componente ser produzido internamente. Outros testes foram feitos, tendo sido consistentes com as hipóteses da TCT. Isso deu a primeira sustentação empírica para toda a discussão acerca dos custos de transação determinando as etapas da cadeia produtiva integradas verticalmente dentro da empresa.

Ainda segundo Fiani (2002, p. 282), Scott Masten publicou, em 1984, um estudo referente às compras de uma empresa americana aeroespacial, encontrando evidências de que aumentam as chances dos componentes serem produzidos internamente quanto maiores os seus graus de complexidade e especificidade.

Outros estudos foram feitos, envolvendo, por exemplo, a decisão da empresa entre empregar seus próprios vendedores ou firmar contratos com representantes autônomos. Em todos eles se verificou evidência empírica de que a verticalização tende a ocorrer quanto maior a especificidade e complexidade da transação.

Adler et. al. (1998, p. 185) examina se as dimensões dos custos de transação relativas à especificidade de ativos, incerteza e incompletude contratual poderiam predizer com segurança o tipo de contrato usado numa troca econômica. Hipóteses oriundas da teoria dos custos de transação foram testadas e os resultados indicaram que as dimensões dos custos de transação são importantes na diferenciação entre os tipos de contrato. 
Balakrishnan e Fox (1993, p. 7-8) testaram as seguintes proposições relacionadas à natureza dos ativos da firma e sua alavancagem:

1. a alavancagem da firma deve ser positivamente relacionada à reempregabilidade dos seus ativos;

2. a alavancagem da firma será positivamente relacionada aos seus investimentos em ativos tangíveis;

3. a alavancagem da firma será negativamente relacionada aos seus investimentos em ativos intangíveis (específicos).

4. a alavancagem de uma firma será positivamente relacionada aos seus investimentos em ativos reputacionais que sinalizam compromisso com o mercado do produto em que compete.

Os autores analisaram duas variáveis representativas de ativos intangíveis: (1) despesas de P\&D sobre vendas líquidas; e (2) despesas de propaganda sobre vendas líquidas. Como esperado, a variável de intensidade em P\&D mostra uma relação negativa e estatisticamente significante com o endividamento. Entretanto, ao contrário do esperado, as despesas de propaganda apresentam uma relação positiva e significante com 0 endividamento. Isso pode significar que as empresas que investem em ativos (marcas, por exemplo) que aumentem sua reputação, conseguem maior alavancagem financeira. As marcas são como bens duráveis que exigem altos níveis de investimento e, por isso, altas despesas com propaganda podem ser entendidas como um sinal de que a empresa pretende continuar no mercado.

A evidência desse estudo de 295 firmas sugere, fortemente, que as características únicas dos ativos específicos e habilidades da firma são de longe os mais importantes determinantes da estrutura de capital.

Cushing (1993, p. 16) desenvolveu um modelo de estimação de um índice de medida de especificidade de ativos baseado no valor de liquidação da firma e a distribuição proporcional do valor pré-liquidação de seus ativos. Segundo ele, o valor de liquidação mensura o melhor segundo uso de um ativo que está sendo reempregado. A razão entre o valor de liquidação e o total de ativos, possuídos pela firma antes da liquidação, mede a eficiência relativa com que os ativos são convertidos para o seu próximo melhor uso.
Para controlar as diferenças entre os procedimentos de liquidação, uma variável dummy foi adicionada, que representa o método de liquidação (fusão, aquisição, falência e liquidação voluntária). Das quatro possibilidades de processo de liquidação identificadas por Cushing (1993, p.18), este utilizou os dados referentes apenas aos casos de falência e de liquidação voluntária. A escolha justifica-se pelo fato de que, nessas duas circunstâncias, o ativo passa a ser empregado em seu segundo melhor uso, enquanto nas outras duas hipóteses, fusão e aquisição de empresas, ocorre a continuidade da utilização dos ativos na sua atividade original, não sendo úteis, portanto, para o teste proposto pelo referido autor.

Os resultados encontrados por Cushing (1993, p. 19) são no sentido de que o valor de liquidação é uma boa proxy para a especificidade do ativo, o qual captura o valor do próximo melhor uso daquele ativo. Uma relação positiva estatisticamente significativa foi encontrada entre o índice de especificidade estimado e a alavancagem financeira, suportando a predição teórica.

Rocha (2002, p. 255) refere o estudo de J. Sutton que, por sua vez, distingue os custos irrecuperáveis em duas categorias: (1) exógenos; e (2) endógenos. Os exógenos são representados por investimentos que são realizados apenas uma vez, não tendo desdobramentos. Isso ocorre, por exemplo, no investimento em uma planta com processos de alta intensidade de capital. Custos irrecuperáveis endógenos geram desdobramentos porque são parte essencial do processo de concorrência da indústria. Nessa categoria se encontram investimentos em propaganda e P\&D. Enquanto barreiras à entrada a partir de custos irrecuperáveis exógenos se esgotam e tendem a desaparecer ou perder sua importância com o crescimento do mercado, a presença de custos irrecuperáveis endógenos permite, em contrapartida, o estabelecimento de barreiras à entrada e saída de longo prazo. Os resultados empíricos encontrados por Sutton para propaganda (1988) e para P\&D (1998) confirmam sua hipótese, mostrando que indústrias onde essas características são relevantes têm maior grau de concentração.

Kayo (2002, p. 1) desenvolveu estudo procurando mostrar evidências de que as empresas intangível-intensivas apresentam diferenças 
significativas em relação às empresas tangívelintensivas no que diz respeito à estrutura de capital e ao risco. Esse objetivo é perseguido por meio de uma pesquisa realizada com empresas do Brasil e dos Estados Unidos no período entre 1998 e 2001. Para se orientar todo o processo investigativo e se responder à questão levantada no problema de pesquisa, foram estabelecidas as seguintes hipóteses com relação à comparação entre empresas intangível e tangível-intensivas: (1) não existe diferença entre as médias de endividamento; (2) não existe diferença entre as médias de risco (beta); e (3) não existem fatores, ou variáveis, que as diferenciem.

O teste da primeira hipótese evidencia que, tanto na amostra de empresas brasileiras quanto norte-americanas, o nível de endividamento é significativamente menor nas empresas intangívelintensivas. O teste da segunda hipótese não apresenta resultados tão significativos quanto o teste da primeira. Ainda assim, os resultados mostram que as empresas intangível-intensivas apresentam um nível de risco maior que as tangível-intensivas. O teste da terceira hipótese, que procura identificar as variáveis capazes de diferenciar as empresas intangível e tangível-intensivas, mostra um grande poder discriminatório de apenas uma variável: o endividamento. Em todos os casos analisados e para as amostras de empresas norte-americanas e brasileiras, essa é a única variável sempre presente nos modelos.

Ainda de acordo com Kayo (2002, p. 32), Titman e Wessels (1988) analisam a relação entre o endividamento das empresas e uma série de variáveis que a teoria financeira aponta como determinantes. $O$ fator singularidade (aquilo que diferencia as empresas, tais como marca, pessoal, formulações, patentes e outros ativos intangíveis), por sua vez, também pode ser assumido como representativo da intangibilidade de uma empresa. Desse fator, fazem parte variáveis como despesas com pesquisa e desenvolvimento e vendas (que incluem despesas como propaganda). Titman e Wessels encontraram uma relação negativa e significante entre o fator singularidade $e$ o endividamento. Esse resultado pode indicar que as empresas intangível-intensivas tendem a apresentar um baixo nível de endividamento.
Nakamura (1992, p. 123) buscou investigar, tomando uma amostra representativa de empresas sediadas no Brasil, a validade de algumas das principais proposições da teoria da estrutura de capital, especialmente aquelas que já vêm sendo testadas em trabalhos empíricos desenvolvidos sobretudo nos Estados Unidos. As afirmações de que a existência de ativos tangíveis e o tamanho da empresa são fatores de determinação da estrutura de capital foram confirmadas. Outro resultado importante corresponde à constatação de que o setor de atividade, incluindo grau de concentração de cada um, constitui-se em um fator de diferenciação de endividamento entre as empresas, confirmando os resultados já obtidos em outros trabalhos. Da mesma forma, o tipo de capital da empresa, privado nacional, privado estrangeiro e estatal, também ajuda a agrupar empresas com níveis de endividamento semelhantes.

Belli (2002) compara as características patrimoniais e de resultados entre as 100 empresas que compõem o índice Nasdaq e as 30 que compõem o índice Dow Jones e encontra resultados que tendem a confirmar que a existência de ativos específicos reduz o nível de endividamento das empresas que formam o primeiro grupo. $\mathrm{O}$ autor analisa diversos índices, os quais divide em três grandes grupos: índices de endividamento, índices de composição e características do ativo e índices de resultado, tendo constatado que as empresas que compõem o índice Nasdaq apresentam menor endividamento do que as do Dow Jones, e que esse endividamento concentra-se no curto prazo.

\section{HIPÓTESE}

A partir dos fundamentos teóricos apresentados até aqui e considerando as evidências empíricas anteriormente relatadas, pretende-se testar a validade da seguinte hipótese: existe uma associação inversa entre o grau de concentração de um mercado ou setor e os níveis de endividamento geral e de longo prazo das empresas inseridas neles.

Confirmada essa expectativa, poder-se-ia afirmar que as empresas que reúnem baixos índices de endividamento geral e de longo prazo e estão inseridas em um mercado com alto grau de concentração têm, provavelmente, maior grau de especificidade de ativos, uma vez que esse atributo 
é apontado (BALAKRISHNAN \& FOX, 1993; CUSHING, 1993; KAYO, 2002; SUTTON apud RO$\mathrm{CHA}, 2002)$ como causa tanto do maior grau de concentração como da menor alavancagem.

Contrariamente, uma empresa atuando em um mercado com menor grau de concentração, e que apresente altos níveis de endividamento geral e de longo prazo, provavelmente será uma empresa com menor grau de especificidade de ativos.

Conforme sustentado pela TCT, maior grau de especificidade de ativos implica em maiores riscos para o empreendimento, o que eleva a taxa de juros dos empréstimos de terceiros, fazendo com que a firma prefira financiar seus investimentos com capitais próprios. Por outro lado, mercados ou setores industriais com maior grau de concentração também têm como característica uma presença maior de ativos específicos, o que, aliás, juntamente com a figura dos sunk costs, é visto como uma das causas dessa maior concentração.

A formulação da hipótese foi condicionada pela limitação dos dados utilizados, tendo em vista que a variável proxy indicada para medir o grau de especificidade de ativos seria aquela utilizada por Cushing (1993, p. 17), baseada na relação entre o valor de liquidação de um ativo e o seu valor préliquidação; o valor de liquidação referir-se-ia ao segundo melhor uso de um determinado bem, e quanto mais específico esse ativo, maior a diferença entre esses valores. Os dados relativos aos valores de liquidação dos ativos da amostra selecionada, entretanto, não são disponibilizados pelas empresas. $\mathrm{Na}$ verdade, esses valores, via de regra, sequer são apurados.

Dessa forma, não se dispõe de dados referentes ao estimador da variável especificidade de ativos, que é apontada pela doutrina como um dos fatores determinantes principais da concentração industrial e da estrutura de capitais da empresa. Isso, obviamente, impõe limitações ao trabalho e a suas conclusões.

A hipótese é testada a seguir.

\section{DADOS E METODOLOGIA}

Trata-se de uma amostra cross-sectional inicialmente formada pelas 500 maiores empresas do Brasil segundo a publicação anual Exame Melhores e
Maiores de 2002. Foram descartadas da amostra, primeiramente, os casos de missing data. Após, restringiu-se a amostra aos casos de indústrias com controle acionário brasileiro; assim, foram excluídas as empresas comerciais, as prestadoras de serviços, as com controle estrangeiro e as estatais, a fim de evitar que as idiossincrasias desses tipos de empresas tornassem desnecessariamente complexa a interpretação dos resultados. A amostra final restou composta de 125 indústrias com controle acionário brasileiro, pertencentes a quatorze setores diferentes, conforme classificação da Revista Exame, cujos dados coletados se referem ao exercício de 2001 (Anexo A).

Foram selecionadas as seguintes variáveis para testar as hipóteses formuladas acima:

1. Grau de concentração industrial do setor (con): calculado de acordo com a razão de concentração de ordem quatro, $\mathrm{CR}(4)$, índice que, segundo Resende e Boff (2002), mede o poder de mercado exercido pelas quatro maiores empresas do setor. Ele foi calculado somando-se os percentuais de participação das quatro maiores empresas de cada setor, indicados pela Revista Exame.

2. Endividamento geral (end): obtido pela divisão do passivo exigível pelo ativo total. Representa a participação dos capitais de terceiros no financiamento das atividades da empresa e é equivalente ao conceito de alavancagem (leverage) normalmente empregado nas pesquisas empíricas na área de finanças.

3. Endividamento de longo prazo (elp): obtido pela divisão do passivo exigível a longo prazo pelo passivo exigível total.

Como variáveis adicionais, a serem utilizadas para auxiliar na explicação dos resultados, foram selecionadas, ainda, as seguintes:

1. Grau de imobilização (gim): obtido pela divisão do ativo permanente pelo ativo total.

2. Ativo total ajustado (att): o ativo total da empresa acrescido das duplicatas descontadas, que foram reclassificadas no passivo circulante, expresso em milhões de reais.

Para resolver o problema de pesquisa proposto, empregar-se-á a cluster analysis que, segundo Hair Jr. et. al. (1998, p. 473), é um grupo de técnicas de análise multivariada cujo propósito primário é reunir 
objetos baseando-se nas suas características. Ela classifica objetos (p. ex., respondentes, produtos ou outras entidades) segundo aquilo que cada um deles tem de similar a outros dentro do grupo com respeito a um critério de seleção predeterminado. O grupo resultante deve, então, exibir um alto grau de homogeneidade interna (within-cluster) e alta heterogeneidade externa (between-cluster).

No teste de multicolinearidade, através da análise dos coeficientes de correlações de Pearson entre as variáveis, pode-se constatar que os níveis são, em geral, baixos ou aceitáveis, sendo que o maior coeficiente foi verificado entre o endividamento geral e o de longo prazo, equivalente a 0,715 . Os valores foram padronizados devido às diferenças de magnitude existentes entre as variáveis, o que distorceria os resultados da análise.

É com base na medida de similaridade ou de dissimilaridade que os objetos são agrupados na análise cluster. Optou-se pela distância euclidiana quadrada, pois: (1) tratam-se de variáveis métricas; (2) as diferenças de magnitude entre os casos têm relevância na classificação, afastando, assim, as medidas correlacionais; (3) a distância euclidiana é a mais utilizada, sendo que muitas das outras medidas são apenas variantes dela.

Como algoritmo de agrupamento, foi escolhido o Ward's method. A razão para a escolha dessa técnica é aquela ressaltada por Hair Jr. et. al. (1998, p. 496), segundo os quais ela minimiza as diferenças dentro do grupo e elimina o problema da cadeia ou corrente prolongada identificado no single linkage method.

Nesse momento, antes de processar a análise, convém estabelecer uma faixa de número de grupos julgada adequada, tendo em vista os objetivos da pesquisa e o conhecimento que se tem do universo estudado. Para os fins deste estudo, estabelece-se como solução final desejada um número de dois clusters: em um estariam as empresas com um provável maior grau de especificidade de ativos; e no outro, estariam aquelas com provável menor grau de especificidade de ativos.

Depois de processada a análise, as empresas foram classificadas em dois clusters, sendo que as médias ou centróides de cada um deles, com os respectivos valores $F$ e níveis de significância, são apresentados no Tabela 2 abaixo.

Tabela 2 - Resultados da Análise de Cluster

\begin{tabular}{l|c|c|cc} 
Itens & Con & End & elp & Tamanho do cluster \\
Cluster 1 & $40 \%$ & $73 \%$ & $45 \%$ & 33 \\
\hline Cluster 2 & $47 \%$ & $43 \%$ & $17 \%$ & 92 \\
\hline Valor $F$ & 5,732 & 75,222 & 136,089 & \\
\hline Significância & 0,018 & 0,000 & 0,000 &
\end{tabular}

Conforme ressaltado em Johnson e Wichern (1998, p. 726), não existe, na análise cluster, a melhor solução ou o melhor agrupamento, mas, sim, bons e maus agrupamentos. No presente caso, a solução encontrada pode ser considerada boa, uma vez que foram formados dois clusters com características bastante distintas, mostrando um alto poder de discriminação das variáveis. Isso é comprovado pelos valores $F$ e pelos níveis de significância de cada variável: inferiores a 0,01 para as variáveis endividamento geral (end) e endividamento de longo prazo (elp), ou seja, com grau de confiança superior a 99\%; e inferior a 0,02 para a variável concentração industrial (con), o que equivale a um grau de confiança de $98 \%$.

\section{INTERPRETAÇÃO E VALIDAÇÃO DOS RESULTADOS}

Os resultados encontrados confirmam as expectativas iniciais no sentido de que, primeiramente, 0 endividamento geral e o de longo prazo estão associados com o grau de concentração da indústria na qual está inserida a empresa. O Cluster 2 apresenta um grau médio de concentração industrial superior ao Cluster 1; por outro lado, aquele tem níveis médios de endividamento geral e de longo prazo muito inferiores a este último.

Dessa forma, as empresas classificadas no Cluster 2 são, possivelmente, as que apresentam maior grau de especificidade de ativos, enquanto as que foram classificadas no Cluster 1 são aquelas que, 
possivelmente, tenham menor presença de ativos específicos.

Um outro teste pode ser realizado a fim de confirmar alguns achados de pesquisas anteriores e, também, auxiliar a perfilar os grupos, através da utiliza- ção das variáveis grau de imobilização (gim) e ativo total ajustado (att). Depois de processado um teste de diferença de médias entre os clusters com relação a essas variáveis, foram encontrados os resultados mostrados no Tabela 3.

Tabela 3 - Teste de Diferença de Médias

\begin{tabular}{|c|c|c|c|}
\hline Itens & gim & att & Tamanho do cluster \\
\hline Cluster 1 & $58 \%$ & R\$ 724 milhões & 33 \\
\hline Cluster 2 & $48 \%$ & R\$ 596 milhões & 92 \\
\hline Significância & 0,030 & 0,597 & \\
\hline
\end{tabular}

O teste acima permite, primeiramente, confirmar os achados anteriores, tais como os referidos por Balakrishnan e Fox (1993, p. 14), no sentido de que a alavancagem da firma será positivamente relacionada com seus investimentos em ativos tangíveis. No presente caso, o Cluster 1 , mais endividado, apresenta um grau de imobilização médio superior ao Cluster 2, o que ajudaria a explicar o seu maior potencial para a captação de empréstimos, uma vez que possui mais ativos tangíveis (possivelmente, também, menos específicos) para garantir eventuais riscos de insolvência.

Os resultado encontrados por Nakamura (1992, p. 123) em relação ao porte da empresa como elemento facilitador da tomada de empréstimos de terceiros, por sua vez, não se confirmaram, uma vez que as médias dos ativos totais ajustados das empresas classificadas nos clusters 1 e 2 não são significativamente diferentes, embora as do primeiro sejam maiores.

Como procedimento de validação, aplicou-se a análise discriminante, tendo-se obtido $93,6 \%$ de acurácia tanto na classificação com os dados originais como na validação cruzada (cross-validated), utilizando-se as variáveis concentração industrial (con), endividamento geral (end) e endividamento de longo prazo (elp).

\section{CONCLUSÕES}

Os desenvolvimentos da TCT e as evidências empíricas relatadas em pesquisas anteriores não deixam dúvidas quanto à importância da especificidade de ativos na determinação da estrutura de capitais de uma firma, bem como das características do mercado na qual ela atua, em particular o seu grau de concentração.

Os resultados encontrados, no presente trabaIho, confirmam, de uma maneira geral, aqueles relatados por outros pesquisadores. Encontrou-se forte associação entre endividamento geral, endividamento de longo prazo e grau de concentração industrial, permitindo a formação de clusters significativamente distintos.

O primeiro cluster apresentou um grau médio de concentração industrial menor e níveis de endividamento geral e longo prazo maiores, permitindo afirmar que tal grupo seria formado por firmas com provável menor grau de especificidade de ativos. Já o segundo cluster apresenta características opostas: maior concentração e menores níveis de endividamento, o que permite afirmar tratar-se de empresas com provável maior grau de especificidade de ativos.

Como visto, essa constatação tem suporte na TCT, segundo a qual um maior grau de especificidade de ativos implica em maiores riscos para o empreendimento, o que eleva a taxa de juros dos empréstimos de terceiros, fazendo com que a firma prefira financiar seus investimentos com capitais próprios (estrutura de governança hierárquica). Por outro lado, mercados ou setores industriais com maior grau de concentração também têm como característica uma presença maior de ativos específicos, o que, aliás, juntamente com a figura dos sunk costs, é visto como uma das causas dessa maior concentração.

As limitações da pesquisa ficam por conta, primeiramente, da indisponibilidade de dados acerca 
de variáveis proxy para a especificidade de ativos, tais como a relação entre o valor de liquidação de um bem e seu valor pré-liquidação. Outros aspectos dizem respeito, por exemplo, à própria base de dados utilizada, em que determinados setores são agrupamentos de outros setores, tais como siderurgia e metalurgia, química e petroquímica, higiene, limpeza e cosméticos etc. É óbvio que o cálculo do grau de concentração desses setores seria mais preciso se levasse em conta cada um dos mercados separadamente.
A presente pesquisa pode ser ampliada, por exemplo, com a introdução de dados relativos aos gastos com pesquisa e desenvolvimento e às despesas com propaganda. Esses itens são apontados pela doutrina como ativos específicos intangíveis, e dificilmente registrados no balanço patrimonial das empresas. Além disso, pode-se testar as hipóteses tomandose por base um número maior de períodos, eliminando-se, assim, a influência de comportamentos singulares temporários em relação a determinada variável.

\section{REFERÊNCIAS BIBLIOGRÁFICAS}

ADLER, Terry R.; SCHERER, Robert F.; BARTON, Sidney L.; KATERBERG, Ralph. An Empirical Test of Transaction Cost Theory: validating contract typology. Journal of Applied Management Studies, v. 7, n. 2, p. 185-200, 1998.

BALAKRISHNAN, Srinivasan; FOX, Isaac. Asset specifity, firm heterogeneity and capital structure. Strategic Management Journal, v. 14, p. 3-16, 1993.

BELLI, Márcio Marcelo. Características patrimoniais e de resultados das empresas que compõem o Nasdaq - 100. Dissertação (Mestrado em Controladoria e Contabilidade). Faculdade de Economia, Administração e Contabilidade, Universidade de São Paulo, 2002.

CHABAUD, D. Asset Specificity and Work Organization: Evidence from the Automotive Industry. Paris: s.d. Disponível em:<chabaud@ paris.u-cergy.fr > Acesso em: 8. jun. 2003.

COASE, Ronald. The Nature of the Firm. Economica, v. 4, p.386405, 1937.

CUSHING, Woodrow W. Asset Specificity and Corporate Governance: an Empirical Test. Managerial Finance, v. 22, n. 2, 1996.

EXAME MELHORES E MAIORES. São Paulo: Editora Abril, 2002. Anual.

FARINA, Elizabeth M. M. et al. Competitividade: mercados, Estado e organizações. São Paulo: Singular, 1997.

FIANI, Ronaldo. Teoria dos Custos de Transação. In Economia Industrial. Rio de Janeiro: Campus, 2002.

GHOSHAL, Sumantra; MORAN, Peter. Bad practice: a critique of the transaction cost theory. Academy of Management Review, v. 21, n. 1, p. 13-47, 1996.

GUEDES, Sebastião Neto Ribeiro. Observações sobre a economia institucional: há possibilidade de convergência entre o velho e o novo institucionalismo? V Encontro Nacional de Economia Política, Fortaleza, 21 a 25/6/2000.

HAIR JUNIOR, Joseph F.; ANDERSON, Rolph E.; TATHAM, Ronald L. et al. Multivariate data analysis: with readings. 5.ed. Upper Saddle River, New Jersey: Prentice-Hall, 1998. 730 p.
INTERNATIONAL ACCOUNTING STANDARDS BOARD. Estrutura conceitual para a elaboração e apresentação das demonstrações contábeis. Normas Internacionais de Contabilidade, 2001.

JOHNSON, Richard A., WICHERN, Dean W. Applied Multivariate Statistical Analysis. $4^{\text {a }}$ ed. Upper Saddle River, New Jersey: Prentice-Hall, 1998.

KAYO, Eduardo Kazuo. A estrutura de capital e o risco das empresas tangível e intangível-intensivas: uma contribuição ao estudo da valoração de empresas. Tese (Doutorado em Administração). Faculdade de Economia, Administração e Contabilidade, Universidade de São Paulo, 2002.

KUPFER, David; HASENCLEVER, Lia. Economia Industrial. Rio de Janeiro: Campus, 2002.

MARTINS, Eliseu. Avaliação de empresas: da mensuração contábil à econômica. Eliseu Martins (organizador). São Paulo: Atlas, 2001.

NAKAMURA, W. T. Estrutura de Capital das Empresas no Brasil. Tese (Doutorado em Contabilidade). Faculdade de Economia, Administração e Contabilidade, Universidade de São Paulo, 1992.

NICKERSON, J.; HAMILTON, B.;WADA, T. Market Position, Resource Profile, and Governance: Linking Porter and Williamson in the Context of International Courier and Small Package Services in Japan. Saint Louis, MO: s.d

PHAN, D.; SOMMER, T. Governance and technological change: Transaction Costs in Telco-Equipment Supplier Network. Amsterdam: Elsevier Science, 1999. Disponível em: <http://www-eco.enst-bretagne.fr/Recherche/Biblio/Denis/ Transac.html> . Acesso em: 8 jun. 2003.

PLUNKET, A; SAUSSIER, S. Human Asset Specificity in Alternative Theories of the firm: How to rule out competing views? Paris: Université de Paris, 2002.

RESENDE, Marcelo; BOFF, Hugo. Concentração industrial. In Economia Industrial. Rio de Janeiro: Campus, 2002.

ROCHA, Frederico. Prevenção estratégica à entrada. In Economia Industrial. Rio de Janeiro: Campus, 2002. 
WILLAMETTE UNIVERSITY. The Simplest, Most Elementary Case for the Utility of Transaction Cost Analysis. Salem, Oregon: s.d. Disponível em: <http:// www.willamette.edu/ fthompso/MgmtCon/Transcost.html>. Acesso em: 8 jun. 2003.

WILLIAMSON, Oliver E. The Economic Institution of Capitalism: Firms, Markets, Relational Contracting. New York: The Free Press, 1985.

Corporate Finance and Corporate Governance. The Journal of Finance, v. 43, p. 567-591, jul. 1988.
Comparative Economic Organization: The Analysis of Discrete Structural Alternatives. Administrative Science Quarterly, 36, p. 269-296, jun. 1991.

Strateging, Economizing, and Economic Organization. Strategic Management Journal, 12, p. 75-94, 1991.

Transaction Cost Economics and Organization Theory. Journal of Industrial and Corporative Change, 2, p. 107-156, 1993.

Mechanisms of Governance. New York: Oxford University Press. 1996.

NOTA:

Endereço dos autores:

MARCELO COLETTO POHLMANN

Av. Ipiranga, 6681

Porto Algre - RS

90619-900

ANDSON BRAGA DE AGUIAR

ALDO BERTOLUCCI

ELISEU MARTINS

Av. Prof. Lucianos Gualberto, 908 - Cidade Universitária

São Paulo - SP

05508-900 
Anexo A: Dados da amostra e respectiva classificação nos clusters

\begin{tabular}{|c|c|c|c|c|c|c|c|c|c|}
\hline No. & Ordem & Empresa & Setor & con & end & elp & gim & att & cluster \\
\hline 1 & 35 & Sadia & Alimentos & 40 & 60 & 31 & 49 & 1.312 & 1 \\
\hline 2 & 46 & Perdigão Agroindustrial & Alimentos & 40 & 71 & 31 & 43 & 1.082 & 1 \\
\hline 3 & 191 & Itambé & Alimentos & 40 & 55 & 16 & 42 & 171 & 2 \\
\hline 4 & 193 & Cosan & Alimentos & 40 & 65 & 14 & 58 & 294 & 2 \\
\hline 5 & 195 & Caramuru Alimentos & Alimentos & 40 & 83 & 35 & 31 & 156 & 1 \\
\hline 6 & 196 & Avipal & Alimentos & 40 & 48 & 15 & 59 & 370 & 2 \\
\hline 7 & 206 & Aurora & Alimentos & 40 & 54 & 24 & 43 & 147 & 2 \\
\hline 8 & 232 & Moinhos Cruzeiro do Sul & Alimentos & 40 & 77 & 11 & 32 & 137 & 2 \\
\hline 9 & 245 & Elegê & Alimentos & 40 & 39 & 16 & 52 & 154 & 2 \\
\hline 10 & 277 & Garoto & Alimentos & 40 & 50 & 27 & 47 & 151 & 2 \\
\hline 11 & 280 & Bianchini & Alimentos & 40 & 35 & 4 & 44 & 55 & 2 \\
\hline 12 & 289 & Granja Rezende & Alimentos & 40 & 28 & 14 & 47 & 304 & 2 \\
\hline 13 & 290 & Braswey & Alimentos & 40 & 70 & 8 & 49 & 210 & 2 \\
\hline 14 & 298 & Fábrica Fortaleza & Alimentos & 40 & 13 & 13 & 55 & 410 & 2 \\
\hline 15 & 356 & Josapar & Alimentos & 40 & 78 & 38 & 57 & 116 & 1 \\
\hline 16 & 388 & Centúria & Alimentos & 40 & 86 & 0 & 1 & 28 & 2 \\
\hline 17 & 395 & Usina Barra & Alimentos & 40 & 90 & 58 & 55 & 278 & 1 \\
\hline 18 & 410 & Usina Caete & Alimentos & 40 & 40 & 20 & 40 & 297 & 2 \\
\hline 19 & 411 & Usina São Martinho & Alimentos & 40 & 53 & 26 & 65 & 246 & 2 \\
\hline 20 & 428 & $\mathrm{CCL}$ & Alimentos & 40 & 60 & 33 & 37 & 72 & 1 \\
\hline 21 & 429 & Santa Elisa & Alimentos & 40 & 65 & 38 & 53 & 185 & 1 \\
\hline 22 & 449 & $\mathrm{BF}$ & Alimentos & 40 & 96 & 43 & 38 & 107 & 1 \\
\hline 23 & 492 & Açucareira Carona & Alimentos & 40 & 80 & 55 & 29 & 1.378 & 1 \\
\hline 24 & 496 & Vigor & Alimentos & 40 & 58 & 39 & 51 & 425 & 1 \\
\hline 25 & 498 & Granol & Alimentos & 40 & 61 & 43 & 62 & 81 & 1 \\
\hline 26 & 499 & ABC Inco & Alimentos & 40 & 62 & 37 & 18 & 72 & 1 \\
\hline 27 & 500 & Irmãos Biagi-Usina da Pedra & Alimentos & 40 & 50 & 36 & 53 & 151 & 2 \\
\hline 28 & 15 & Embraer & Automotivo & 25 & 67 & 16 & 17 & 3.385 & 2 \\
\hline 29 & 192 & Marcopolo & Automotivo & 25 & 63 & 22 & 26 & 255 & 2 \\
\hline 30 & 347 & Random Implementos & Automotivo & 25 & 54 & 19 & 32 & 101 & 2 \\
\hline 31 & 374 & Busscar & Automotivo & 25 & 69 & 14 & 42 & 180 & 2 \\
\hline 32 & 8 & CBB/Ambev & Bebidas & 63 & 75 & 47 & 50 & 4.302 & 2 \\
\hline 33 & 302 & Coca-Cola Vonpar & Bebidas & 63 & 24 & 8 & 56 & 223 & 2 \\
\hline 34 & 439 & Cervejaria Astra & Bebidas & 63 & 43 & 12 & 21 & 115 & 2 \\
\hline 35 & 482 & Coca-Cola / Ipiranga & Bebidas & 63 & 38 & 25 & 39 & 77 & 2 \\
\hline 36 & 487 & Antarctica do Sudeste & Bebidas & 63 & 27 & 19 & 1 & 283 & 2 \\
\hline 37 & 117 & Vicunha Têxtil & Confecções e Têxteis & 31 & 61 & 14 & 51 & 606 & 2 \\
\hline 38 & 225 & Coteminas & Confecções e Têxteis & 31 & 27 & 12 & 58 & 648 & 2 \\
\hline 39 & 226 & São Paulo Alpargatas & Confecções e Têxteis & 31 & 38 & 17 & 43 & 295 & 2 \\
\hline 40 & 269 & Grendene Sobral & Confecções e Têxteis & 31 & 25 & 9 & 33 & 192 & 2 \\
\hline 41 & 292 & Azaléia & Confecções e Têxteis & 31 & 38 & 11 & 41 & 249 & 2 \\
\hline 42 & 363 & Teka & Confecções e Têxteis & 31 & 81 & 42 & 50 & 202 & 1 \\
\hline 43 & 385 & Hering & Confecções e Têxteis & 31 & 87 & 51 & 58 & 295 & 1 \\
\hline 44 & 257 & Semp Toshiba AM & Eletroeletrônico & 28 & 22 & 1 & 9 & 325 & 2 \\
\hline 45 & 291 & CCE da Amanzônia & Eletroeletrônico & 28 & 62 & 3 & 14 & 165 & 2 \\
\hline 46 & 319 & Stemac & Eletroeletrônico & 28 & 51 & 6 & 12 & 64 & 2 \\
\hline 47 & 236 & Aché & Farmacêutico & 33 & 41 & 25 & 79 & 335 & 2 \\
\hline 48 & 436 & Biosintética & Farmacêutico & 33 & 61 & 16 & 24 & 60 & 2 \\
\hline 49 & 128 & Natura & Hig., Limp.e Cosméticos & 26 & 83 & 57 & 49 & 200 & 1 \\
\hline 50 & 381 & Klabin Kimberly & Hig., Limp.e Cosméticos & 26 & 30 & 7 & 59 & 177 & 2 \\
\hline 51 & 481 & O Boticário & Hig., Limp.e Cosméticos & 26 & 75 & 36 & 68 & 36 & 1 \\
\hline 52 & 74 & Cimento Rio Branco & Material de Construção & 32 & 52 & 11 & 48 & 806 & 2 \\
\hline 53 & 186 & Tigre & Material de Construção & 32 & 30 & 10 & 42 & 352 & 2 \\
\hline 54 & 238 & Camargo Corrêa Cimentos & Material de Construção & 32 & 52 & 39 & 70 & 469 & 1 \\
\hline 55 & 288 & Duratex & Material de Construção & 32 & 29 & 19 & 66 & 540 & 2 \\
\hline 56 & 295 & Cimento Itaú & Material de Construção & 32 & 18 & 11 & 36 & 585 & 2 \\
\hline 57 & 318 & Concrebrás & Material de Construção & 32 & 63 & 59 & 68 & 393 & 1 \\
\hline 58 & 354 & Cipasa & Material de Construção & 32 & 22 & 8 & 59 & 311 & 2 \\
\hline 59 & 422 & Duratex Coml Exp & Material de Construção & 32 & 30 & 17 & 70 & 295 & 2 \\
\hline 60 & 462 & Eucatex & Material de Construção & 32 & 56 & 28 & 86 & 208 & 1 \\
\hline 61 & 125 & Weg Indústrias & Mecânica & 49 & 52 & 19 & 37 & 475 & 2 \\
\hline 62 & 464 & Usiminas Mecânica & Mecânica & 49 & 33 & 13 & 0 & 321 & 2 \\
\hline 63 & 17 & Vale do Rio Doce & Mineração & 69 & 47 & 31 & 72 & 9.987 & 2 \\
\hline
\end{tabular}




\begin{tabular}{|c|c|c|c|c|c|c|c|c|c|}
\hline No. & Ordem & Empresa & Setor & con & end & elp & gim & att & cluster \\
\hline 64 & 159 & MBR & Mineração & 69 & 60 & 30 & 55 & 641 & 2 \\
\hline 65 & 199 & Ferteco & Mineração & 69 & 75 & 39 & 26 & 355 & 2 \\
\hline 66 & 284 & CBMM & Mineração & 69 & 28 & 10 & 63 & 154 & 2 \\
\hline 67 & 305 & MRN & Mineração & 69 & 30 & 17 & 87 & 399 & 2 \\
\hline 68 & 336 & Nibrasco & Mineração & 69 & 51 & 16 & 40 & 78 & 2 \\
\hline 69 & 351 & Magnesita & Mineração & 69 & 26 & 6 & 54 & 225 & 2 \\
\hline 70 & 73 & VCP & Papel e Celulose & 44 & 17 & 7 & 85 & 1.543 & 2 \\
\hline 71 & 118 & Aracruz Celulose & Papel e Celulose & 44 & 53 & 32 & 71 & 2.445 & 2 \\
\hline 72 & 123 & Suzano & Papel e Celulose & 44 & 57 & 41 & 86 & 1.343 & 1 \\
\hline 73 & 207 & Bahia Sul & Papel e Celulose & 44 & 43 & 27 & 72 & 1.254 & 2 \\
\hline 74 & 223 & Ripasa & Papel e Celulose & 44 & 38 & 29 & 72 & 639 & 2 \\
\hline 75 & 329 & Santher & Papel e Celulose & 44 & 56 & 26 & 71 & 235 & 2 \\
\hline 76 & 380 & Klabin & Papel e Celulose & 44 & 69 & 38 & 80 & 1.851 & 1 \\
\hline 77 & 406 & Inpacel & Papel e Celulose & 44 & 5 & 2 & 53 & 473 & 2 \\
\hline 78 & 442 & Grupo Orsa & Papel e Celulose & 44 & 64 & 41 & 73 & 168 & 1 \\
\hline 79 & 212 & Petroflex & Plásticos e Borracha & 37 & 80 & 53 & 54 & 262 & 1 \\
\hline 80 & 407 & Dixie Toga & Plásticos e Borracha & 37 & 65 & 43 & 67 & 246 & 1 \\
\hline 81 & 472 & Vipal & Plásticos e Borracha & 37 & 49 & 19 & 29 & 158 & 2 \\
\hline 82 & 27 & Copene & Química e Petroquímica & 67 & 59 & 45 & 78 & 2.469 & 2 \\
\hline 83 & 44 & Copesul & Química e Petroquímica & 67 & 58 & 37 & 78 & 1.313 & 2 \\
\hline 84 & 52 & OPP & Química e Petroquímica & 67 & 86 & 54 & 54 & 1.389 & 1 \\
\hline 85 & 59 & Petroquímica União & Química e Petroquímica & 67 & 44 & 23 & 83 & 517 & 2 \\
\hline 86 & 87 & Bayer & Química e Petroquímica & 67 & 69 & 26 & 23 & 488 & 2 \\
\hline 87 & 110 & Trikem & Química e Petroquímica & 67 & 67 & 44 & 57 & 953 & 2 \\
\hline 88 & 126 & IPQ & Química e Petroquímica & 67 & 107 & 59 & 69 & 672 & 1 \\
\hline 89 & 154 & Refinaria de Manguinhos & Química e Petroquímica & 67 & 41 & 3 & 31 & 134 & 2 \\
\hline 90 & 157 & Cia. Petrolífera Marlim & Química e Petroquímica & 67 & 87 & 77 & 78 & 1.261 & 1 \\
\hline 91 & 172 & Polibrasil Resinas & Química e Petroquímica & 67 & 51 & 35 & 60 & 295 & 2 \\
\hline 92 & 184 & Politeno & Química e Petroquímica & 67 & 19 & 8 & 49 & 215 & 2 \\
\hline 93 & 194 & Refinaria Ipiranga & Química e Petroquímica & 67 & 26 & 9 & 49 & 176 & 2 \\
\hline 94 & 204 & Ultrafértil & Química e Petroquímica & 67 & 33 & 14 & 64 & 333 & 2 \\
\hline 95 & 231 & Alunorte & Química e Petroquímica & 67 & 66 & 54 & 71 & 827 & 2 \\
\hline 96 & 256 & Oxiteno Nordeste & Química e Petroquímica & 67 & 35 & 7 & 48 & 255 & 2 \\
\hline 97 & 293 & Heringer & Química e Petroquímica & 67 & 79 & 5 & 13 & 117 & 2 \\
\hline 98 & 321 & Fosfértil & Química e Petroquímica & 67 & 52 & 35 & 70 & 508 & 2 \\
\hline 99 & 371 & Renner Sayerlack & Química e Petroquímica & 67 & 77 & 29 & 27 & 87 & 2 \\
\hline 100 & 419 & Petroquímica Triunfo & Química e Petroquímica & 67 & 22 & 9 & 20 & 708 & 2 \\
\hline 101 & 444 & Oxiteno & Química e Petroquímica & 67 & 16 & 8 & 70 & 367 & 2 \\
\hline 102 & 455 & Copebrás & Química e Petroquímica & 67 & 52 & 36 & 68 & 165 & 2 \\
\hline$\overline{103}$ & 460 & Polialden & Química e Petroquímica & 67 & 27 & 2 & 16 & 214 & 2 \\
\hline 104 & 479 & Ipiranga Química & Química e Petroquímica & 67 & 47 & 6 & 60 & 29 & 2 \\
\hline$\overline{105}$ & 28 & CSN & Siderurgia e Metalurgia & 37 & 66 & 40 & 70 & 6.201 & 1 \\
\hline 106 & 30 & Gerdau & Siderurgia e Metalurgia & 37 & 42 & 28 & 73 & 2.101 & 2 \\
\hline 107 & 86 & Acesita & Siderurgia e Metalurgia & 37 & 68 & 38 & 70 & 1.734 & 1 \\
\hline 108 & 113 & Açominas & Siderurgia e Metalurgia & 37 & 34 & 14 & 78 & 1.693 & 2 \\
\hline 109 & 114 & CBA & Siderurgia e Metalurgia & 37 & 25 & 9 & 47 & 1.364 & 2 \\
\hline 110 & 133 & Caraíba Metais & Siderurgia e Metalurgia & 37 & 61 & 33 & 47 & 503 & 1 \\
\hline 111 & 134 & Albrás & Siderurgia e Metalurgia & 37 & 78 & 54 & 63 & 890 & 1 \\
\hline 112 & 228 & Latasa & Siderurgia e Metalurgia & 37 & 53 & 19 & 60 & 479 & 2 \\
\hline 113 & 317 & Latasa Nordeste & Siderurgia e Metalurgia & 37 & 60 & 33 & 38 & 199 & 1 \\
\hline 114 & 384 & Termomecânica & Siderurgia e Metalurgia & 37 & 24 & 14 & 11 & 183 & 2 \\
\hline 115 & 387 & Crown Cork & Siderurgia e Metalurgia & 37 & 47 & 15 & 43 & 103 & 2 \\
\hline$\overline{116}$ & 432 & Valesul & Siderurgia e Metalurgia & 37 & 19 & 9 & 55 & 126 & 2 \\
\hline 117 & 434 & Eluma & Siderurgia e Metalurgia & 37 & 56 & 11 & 58 & 133 & 2 \\
\hline 118 & 437 & Siderurgia Mineira Metais & Siderurgia e Metalurgia & 37 & 37 & 23 & 76 & 384 & 2 \\
\hline 119 & 454 & Zamprogna & Siderurgia e Metalurgia & 37 & 28 & 6 & 45 & 75 & 2 \\
\hline 120 & 458 & Barra Mansa & Siderurgia e Metalurgia & 37 & 23 & 17 & 74 & 253 & 2 \\
\hline$\overline{121}$ & 463 & Mangels & Siderurgia e Metalurgia & 37 & 56 & 22 & 80 & 90 & 2 \\
\hline 122 & 466 & Inal & Siderurgia e Metalurgia & 37 & 46 & 6 & 1 & 104 & 2 \\
\hline 123 & 478 & Villares Metals & Siderurgia e Metalurgia & 37 & 102 & 75 & 76 & 116 & 1 \\
\hline$\overline{124}$ & 490 & Prada & Siderurgia e Metalurgia & 37 & 26 & 7 & 36 & 39 & 2 \\
\hline 125 & 495 & Níquel Tocantins & Siderurgia e Metalurgia & 37 & 28 & 13 & 74 & 139 & 2 \\
\hline
\end{tabular}

Obs.: As variáveis con, end, elp e gim são expressas em percentuais; a variável att é expressa em R\$ milhões. 